\title{
Mass Hysteria and Adolescent Girl: An Interventional Study
}

\author{
Pushpa Prasad Sharma,' Ajaya Kumar Jha, ${ }^{2}$ Anish Joshi² Ritesh Lamsal' \\ Department of Psychiatry? \\ Department of Paediatrics ${ }^{2}$ \\ Dhulikhel Hospital, Kathmandu University Teaching Hospital
}

\begin{abstract}
Aim: To study factors that may contributory to the problem of "Mass hysteria" in rural school going children before and after psychological intervention.

Method: This study was conducted in Azad Madhyamic Vidyalaya, Baluwa VDC in Dhulikhel over a period of a year. School children suffering from mass hysteria were treated, counseled and later were followed if they had similar hysteric episode.

Results: There were 67 children in the age group of 12 to 14 years, $91 \%$ being females, all were in between 6 th to 9th grades having poor scholastic performance. There was positive family history in $25 \%$. It was commoner in children with lower socio-economic status. Mental illness like anxiety, depressive disorder, determined by using the criteria in DSM IV was found in 13\%. Alcohol abuse and disturbed family dynamics were associated in $33 \%$. More than $50 \%$ of the children with attack were found to have witnessed or been involved in violent activities and in $15 \%$ of the cases there was a history of corporal punishment. After six months of counseling in prospective follow up only $12 \%$ (8 females) had recurrent episodes of the pseudo seizure, which were evident in school drop outs (5\%).
\end{abstract}

Conclusion: Mass hysteria in school children must be reviewed with care as they may be cured with counseling in majority of cases, the repetitive episode of hysteria being more important as they are often found to be linked with psychiatric disorder.

Key words: Mass hysteria, conversion disorder, adolescent problem

\section{Introduction}

"Pseudo seizures", also called "psychogenic seizures", "non-epileptic seizures", or "hysterical seizures" are clinical events that resemble epileptic seizures but are not associated with abnormal cortical electrical discharges. They may occur as a somatoform disorder, with prevalence estimated at $5 \%$ of an outpatient population of adults with epilepsy. ${ }^{1}$ Pseudo-seizures can also manifest in children and adolescents, occurring as early as five or six years of age. ${ }^{2-5}$ Since the advent of enhanced diagnosis by prolonged video EEG monitoring, pseudo-seizures have been studied in detail in adults and in children. ${ }^{2-12}$ However, few data are available about the psychiatric aspects or the outcome of pseudo-seizures in children and adolescents. , $^{3,7,7,11}$
DSM-IV reports the prevalence rate of $0.01-0.3 \%$ for conversion disorder in the general population..$^{13}$ Conversion disorders are more common in adolescents than in younger children and rarely occurs in children less than five years of age. ${ }^{14}$ It is more frequent in females, people from lower socioeconomic groups and in rural populations. ${ }^{15,16}$ Chief conversion symptoms include psychogenic non-epileptic seizures, weakness, aphonia, gait disturbances, abnormal movements, loss of vision and severe pain.

\section{Methods}

This is an intervention study, carried in a community school 'Azad Madhyamic Vidyalaya, Baluwa in VDC Dhulikhel for a period of a year Jan 2008 -2009 
where children who suffered from mass hysteria were interviewed by specifically prepared questionnaire as tool. Detailed examination mental status was performed by a Psychiatrist.

Psychological intervention was done in group therapy. But individual counseling of each adolescent was also carried out. Teachers and parents were also involved for best result, for which they were separately counseled. Teachers were educated and given detail accounts of the problem, such as its possible origin. Simultaneously their responsibilities during the outbreak of mass pseudo-seizures were also explained. Parents also underwent counseling sessions wherein myths and realities about this illness "Mass hysteria" were clarified. After six months of prospective follow up, all children who had recurrence of the episode were re-interviewed.

\section{Results}

During the study period 67 children were found to suffer from the episodes of pseudo-seizures in the community school. All these children were were interviewed in detail.

\section{At the first interaction}

Most of the affected children were in the age group of 12 to 14 years and $91 \%$ were females from the 6 th to 9th grades Family history of similar attacks was found in $25 \%$ of the cases.

Prevalence of the attack was found to be commoner in children with lower socio-economic status.

Some form of mental illness like anxiety, depressive disorder, determined by using the criteria in DSM IV was found in $13 \%$ of cases.

Alcohol abuse and disturbed family dynamics were associated in $33 \%$ of the cases.

Majority of the affected children were found to have poor scholastic performance.

Those children who were found to have below average school performance in their examination grades, which was evident in their school records were labeled as having poor scholastic performance.

More than $50 \%$ of the children with attack were found to have witnessed or been involved in violent activities and in $15 \%$ of the cases there was a history of corporal punishment.

\section{After six months of prospective follow up} $12 \%$ (8cases) had recurrent episodes of the pseudo seizure . All children who had a repeat-attack were females. School drop out was found in 5\% of the cases. Overall outcome after psychological intervention was found to be satisfactory. Also it was found to be very effective in decreasing the recurrence of pseudo seizure.

\section{Discussion}

Freud and Breur first used the term "conversion" to refer to the substitution of a somatic symptom for a repressed idea. ${ }^{17}$ Conversion disorder rarely occurs in children younger than 5 years of age. Despite the fact that conversion disorder has been reported in children as young as 1 - 5 years, in the present study, the minimum age of presentation was 12 years, which is in keeping with the view that age of inception of conversion disorder is unlikely to be before five years of age. ${ }^{18-20}$ All children were adolescents in this study and sex ratio was $10: 1$. About $67 \%$ of patients were in the adolescent age group and a sex ratio 0.9:1 was found in the study done by Jayant et al. ${ }^{21}$ Overall, females outnumbered males, which also goes along with theprevious similar studies. ${ }^{16,22,23}$ Excess of female patients compared to males in conversion disorder is a feature of adult patients, but it has also been seen in many pediatric studies. ${ }^{20,24,25}$ However, some studies have observed no such differences or even a reverse trend. ${ }^{18,26}$ The girl child grows in an atmosphere of inhibited emotional ventilation. This coupled with the pressures of puberty possibly account for the higher occurrence of conversion disorders among girls. ${ }^{27}$ In our study, we have found comorbid anxiety or depression in 13\% of the affected children. Psychiatric illness in the form of mood disorders, anxiety disorders, reactive psychosis are associated features in children and adolescents with pseudo-seizures in the study done by Elaine et al. ${ }^{28}$ Some of the authors have also stressed the importance of childhood sexual abuse as a factor in psudo-seizures. ${ }^{29-32}$ Conversion symptoms are more frequent in relatives of individuals with conversion disorder; however, in this study only $25 \%$ of cases had positive family history of similar attacks. In one previous study, $26.9 \%$ had past history of hysteria where as in this study, none had past history of conversion symptoms. ${ }^{33}$

Treatment of children with mass hysteria generally includes psychotherapy and/or pharmacotherapy. ${ }^{34}$ In this study all the children were treated with psychotherapy in which group and individual counseling were done. Poor scholastic performance was found in majority of cases with similar finding in previous studies. ${ }^{21}$ Poor academic performance leads to stress and failure in coping with the study. Mounting academic pressure leads to pseudo-seizure 
attack which further worsens academic performance. Alcohol abuse and disturbed family dynamics, family conflict was found in $33 \%$ of cases, which suggest children exposed to above mentioned environment are emotionally labile and their stress coping behavior are not strong, hence are susceptible for the episodes of attack. High frequency of family crisis, unresolved grief reactions and problems in family communication are important factors in conversion disorders in children. ${ }^{35}$ Murassey et al attributed family stress to $56.8 \%$ of conversion disorder patients. ${ }^{36}$ Emotional factors and advantages of playing the 'sick role' play a part in continuance of symptoms. The identification of stressors helps in formulating appropriate psycho education of the family and child. Association with witnessing or being involved in violent activities was found in 50\% cases suggesting that those factors may be triggering or perpetuating factors. Identifiable acute precipitating stressors were found in $18.3 \%$ of the patients with conversion disorders reported by Jaipal et al in their study. ${ }^{37}$ Recent stressful life events were evident in $13.8 \%$ and $46 \%$ of children with conversion disorder in the report by Murassey et al and Smith et al respectively. ${ }^{36,20}$ Corporal punishment is a frequently employed tool for shaping behavior in school children in Nepali schools. Its association with the attack in $15 \%$ of children suggests that it is one of the stressors for the attack.

The reduction in the frequency of attack after intervention in teachers and parents is significant in our study and shows the importance of this type of intervention in these patient groups. Our study also reveals that mass hysteria or pseudo-seizures can be effectively dealt with intervention and can be easily conducted in the community. Planned psycho education is an effective intervention, which has also been concluded in the study done by Ravi Shakya. ${ }^{23} \mathrm{We}$ agree with Brunquell that early psychiatric diagnosis and intervention are critical to prevent the behavioral pattern of pseudo-seizures from becoming fully incorporated into the patient's personality and way of life. ${ }^{38}$ Recognition that the seizures are psychogenic and not epileptic, together with identification of the relevant psychiatric and psychosocial factors, are strong therapeutic tools. Based on results from our current and previous studies, it seems that freedom from pseudo-seizures can be achieved for most pediatric patients. ${ }^{3}$

Our study is completed in the community with effective intervention and prospective follow up which has shown to be very cost effective in decreasing the recurrence of mass pseudo-seizures. However, prevalence of co-morbid mental illnesses in the affected children and family mental illnesses or their impact on the mental health of the child needs to be explored in detail. Extreme climatic conditions and its influence on initiating and perpetuating the illness also need further exploration. Likewise bi-directional influence on poor academics and pseudo-seizure attack needs further studies. We recommend comparison of similar problems in rural versus urban areas. Broader community participation and prolonged follow up is strongly suggested. National debate on mass conversion disorder in school children to be initiated with proper resource allocation from government and nongovernmental organization is highly recommended.

\section{Conclusion}

Adolescents girl at their are vulnerable to mass hysteria, more so when poor socioeconomic status were additive risk factor, therefore the problems of mass hysteria needs full attention as they may be cured with counseling provided these are not related to psychiatric disorders.

\section{References}

1. Scott DF. Recognition and diagnostic aspects of nonepileptic seizures. In: Riley TL, Roy A, eds. Pseudoseizures. Baltimore, Md: Williams \& Wilkins 1982; 21-34.

2. Wyllie E, Friedman D, Rothner AD, et al. Psychogenic seizures in children and adolescents: outcome after diagnosis by ictal video and electroencephalographic recording. Pediatr 1990; 85: 480-4.

3. Wyllie E, Friedman D, Lu“ders H, Morris H, Rothner D, Turnbull J. Outcome of psychogenic seizures in children and adolescents compared with adults. Neurology 1991; 41: 742-4.

4. Kramer U, Carmant L, Riviello JJ et al. Psychogenic seizures: video telemetry observations in 27 patients. Pediatr Neurol 1995; 12: 39-41.

5. Lancman ME, Asconape JJ, Graves S, Gibson PA. Psychogenic seizures in children: long-term analysis of 43 cases. J Child Neurol 1994; 9: 404-7.

6. Gates JR, Ramani V, Whalen S, Loewenson R. Ictal characteristics of pseudoseizures. Arch Neurol 1985; 42: 1183-7.

7. Williams DT, Spiegel H, Mostofsky DI. Neurogenic and hysterical seizures in children and adolescents: differential diagnostic and therapeutic considerations. Amer J Psychiatr 1978; 135: 82-6.

8. Finlayson RE, Lucas AR. Pseudoepileptic seizures in children and adolescents. Mayo Clin Proc 1979; 54: 83-7.

9. Gross M. Pseudoepilepsy: a study in adolescent hysteria. Amer J Psychiatr 1979; 136: 210-3.

10. Holmes GL, Sackellares JC, McKiernan J, Ragland M, Dreifuss FE. Evaluation of childhood 
pseudoseizures using EEG telemetry and video tape monitoring. J Pediatr 1980; 97: 554-8.

11. Goodyer IM. Epileptic and pseudoepileptic seizures in childhood and adolescence. J Amer Acad Child Psychiatr. 1985; 24: 3-9.

12. Metrick ME, Ritter FJ, Gates JR, Jacobs MP, Skare SS, Loewenson RB. Nonepileptic events in childhood. Epilepsia 1991; 32: 322-8.

13. American Psychiatric Association. Diagnosis and Statistical Manual of Mental disorders. (2000) 4th edn. Washington, DC: American Psychiatric Association. Text Revision.

14. Nandi DN, Banerjee G, Nandi S et al. Is hysteria on the wane? A community survey of West Bengal, India. Brit J Psychiatry 1992; 160: 87-91.

15. Lazare A. Conversion symptoms. N Engl J Med 1981; 305: 745-8.

16. Ljunberg L. Hysteria: clinical, prognostic and genetic study. Acta Psychiatr Scand 1957; 32: $1-162$.

17. Breuer J, Freud S. Studies on hysteria. In: The Standard of the Complete Psychological Works of Sigmund Freud-Strachey J, ed. (1995) 2. London: Hagarth Press. Originally published in 1893-95.

18. Rock NL. Conversion reactions in childhood: a clinical study on child neurosis. Amer Acad Child Adolesc Psychiatr 1971; 10: 65-94.

19. Goodyer I. Hysterical conversion reactions in childhood. J Child Psychol Psychiatr 1980; 22: 179-88.

20. Smith P, Fairley M, Procopis P. Clinical features of conversion disorder. Arch Dis child 1988; 63: 408- 14

21. Jayant K, Clinical Profile and Outcome of Conversion Disorder in Children in a Tertiary Hospital of North India. J Trop Pediatr 2007. doi:10.1093/tropej/fml088.

22. Stefansson JG, Messina JA, Meyerowitz S. Hysterical neurosis, conversion type: clinical and epidemiological consideration. Acta Psychiatr Scand 1976; 53: 110-38.

23. Shakya R, Epidemic of Hysteria in a School of Rural Eastern Nepal: A Case Report. J Indian Association for Child and Adolescent Mental health 2005. 1(4)

24. Trivedi JK, Singh H, Sinha PK. A clinical study of hysteria in children and adolescents. Indian $J$ Psychiatr 1982; 24: 70-4.

25. Robins E, Neal P. Clinical features of hysteria in children with a note on prognosis. Nerv Child 1953; 10: 246-71.

26. Malhi P, Singhi P. Clinical characteristics and outcome of children and adolescents with conversion disorder. Indian Pediatr 2002; 39: 747- 52.

27. De Sousa A, De Sousa DA. Child Psychiatry. $1^{\text {st }}$ ed. Bombay: Bhalani Book Depot 1987.

28. Elaine Wyllie, Psychiatric Features of Children and Adolescents With Pseudoseizures. Arch Adolesc Med 1999.

29. Gross M. Incestuous rape: a cause for hysterical seizures in four adolescent girls. Amer $J$ Orthopsychiatr 1979; 49: 704-8.

30. Goodwin J, Simms M, Bergman R. Hysterical seizures: a sequel to incest. Amer J Orthopsychiatr 1979; 49: 698-703.

31. Goodwin JM. Childhood sexual abuse and non-epileptic seizures. In: Rowan JA, Gates JR, eds. Non-Epileptic Seizures. Boston, Mass: Butterworth-Heinemann 1993; 181-91.

32. Alper K, Devinsky O, Perrine K, Vazquez B, Luciano D. Nonepileptic seizures and childhood sexual and physical abuse. Neurology 1993; 43: 1950-3.

33. Bendefeidt F, Miller LL, Leedwig TM. Cognitive hysteria. Arch Gen Psychiatr 1976; 33: 12504.

34. Cloninger CR. Somatoform and dissociative disorders. In: The Medical Basis of PsychiatryWinokur G, Clayton PJ, eds. 1994 2nd. Philadelphia: WB Saunders. 169-92.

35. Maloney M. Diagnosing hysterical conversion reaction in children. J Pediatr 1980; 97: 101620.

36. Murase S, Sugiyama T, Ishii T, Wakako R, Ohta T. Polysymptomatic conversion disorder in childhood and adolescence in Japan. Psychother Psychosom 2000; 69: 132-5.

37. Clinical Profile of Pediatric Somatoform Disorders JAIPAL Manuscript received: December2, 2005; Initial review completed: April 18, 2006; Revision accepted: July 20, 2007.

38. Brunquell PJ. Psychogenic seizures in children. Int'l J Pediatr 1995; 10(suppl 1): 47-54. 